\title{
Enhancing a Building Information Model for an Existing Building with Data from a Sustainable Facility Management Database
}

\author{
Ryan Loeh $^{1}$, Jess W. Everett ${ }^{2, *}$, William T. Riddell ${ }^{2} \mathbb{D}$ and Douglas B. Cleary ${ }^{2}$ \\ 1 Hunt Engineering Company, Malvern, PA 19355, USA; rloeh@huntengineering.com \\ 2 Department of Civil \& Environmental Engineering, Rowan University, Glassboro, NJ 08028, USA; \\ riddell@rowan.edu (W.T.R.); cleary@rowan.edu (D.B.C.) \\ * Correspondence: everett@rowan.edu
}

Citation: Loeh, R.; Everett, J.W.; Riddell, W.T.; Cleary, D.B. Enhancing a Building Information Model for an Existing Building with Data from a Sustainable Facility Management Database. Sustainability 2021, 13, 7014 https://doi.org/10.3390/su13137014

Academic Editors: Alex Opoku, Jeoung Yul Lee and Ali BahadoriJahromi

Received: 4 May 2021

Accepted: 15 June 2021

Published: 22 June 2021

Publisher's Note: MDPI stays neutral with regard to jurisdictional claims in published maps and institutional affiliations.

Copyright: (C) 2021 by the authors. Licensee MDPI, Basel, Switzerland. This article is an open access article distributed under the terms and conditions of the Creative Commons Attribution (CC BY) license (https:// creativecommons.org/licenses/by/ $4.0 /)$.

\begin{abstract}
This study investigates the feasibility and benefits of transferring data between Autodesk Revit (used for building information modeling (BIM)) and BUILDER SMS (used for sustainable facility management (SFM)). Two data transfer methods were evaluated using a case study; one involved entirely manual data transfer, the other a combination of manual and automatic. Of the data transfer methods evaluated, the manual/automated hybrid was determined to be the best option, especially when regular updates are envisioned. The case study produced an enhanced BIM model that can be used to support sustainable facility management, called here an SFM-enhanced BIM model. An integration workflow is proposed for efficiently creating future SFM-enhanced BIM models. A focus group of facilities management professionals evaluated the case study BIM model. The focus group was most interested in the visualization capabilities-e.g., filtered views for condition assessments-and the ability to view the BIM model on a tablet/mobile device during on-site operation and maintenance activities.
\end{abstract}

Keywords: building information modeling; sustainable facilities management; Autodesk Revit; BUILDER SMS; data integration

\section{Introduction}

Facility management (FM) has been defined as, "the process by which an organization delivers and sustains support services in a quality environment to meet strategic needs [1]." FM can comprise over $80 \%$ of the costs associated with a building over its lifetime, but the importance of FM is often overlooked [2]. It provides an integrated approach to maintaining and improving a building to support efficient and effective maintenance and day-to-day operations [3]. Computerized maintenance management systems (CMMS) can be used to store and access updatable building information for FM [4-6].

Sustainable facilities management (SFM) is FM with a particular focus on sustainability issues, i.e., reducing a building's impact on its occupants and the environment [7]. BUILDER Sustainable Management System (BUILDER SMS) is an example of a CMMS for SFM [8]. BUILDER SMS is used by the US military and others to manage hundreds of millions of square feet of building area. However, no studies in the literature have been identified that focus on it.

Building information modeling (BIM) refers to the process of creating a data-rich three-dimensional (3D) model of a building. BIM models are superior to traditional twodimensional CAD drawings because they can be displayed in two or three dimensions, a variety of information can be associated with elements, and they are interoperable between different disciplines, e.g., design, construction, operation, maintenance, space allocation, and renovation $[9,10]$. A BIM element is an individual object in a model, e.g., a window, door, wall, sink, light fixture, or furnace. Type properties are common to multiple elements, 
e.g., a particular model of window used multiple times in a given building. Instance properties can be applied to a single element, e.g., one particular window is assigned one particular height. Links to images and documents can also be attached to elements.

BIM can represent both physical and functional characteristics of a building [11], encouraging collaboration among stakeholders to develop and use data-rich building representations [12-14]. BIM models that contain essential information for all phases of a building's life cycle enable a seamless transition from design to renovation and provide a reliable place to store and access information $[15,16]$. BIM software can be used to support FM or SFM by associating relevant information-including condition assessments and documents-with physical elements of a building, e.g., windows, lights, toilets, and HVAC equipment. Autodesk Revit [17] is a popular BIM authoring software. It has been the subject of BIM research, e.g., Yin et al. [18]; Ede, Olofinnade, and Sodipo [19]; Orr et al. [20]; and $\mathrm{Lin}$ and $\mathrm{Su}$ [21].

While BIM models are best started during a building's design phase, they can be created from scratch for existing buildings. A 3D laser scanner can be used to create a point cloud of an existing building [22]. A point cloud is a set of data points in space, each assigned a color. A point cloud can be viewed as a 360 degree image of the interior or exterior of a building or imported into BIM software and traced to create a 3D building model.

Here, an SFM-enhanced BIM model is defined as a BIM model that can be used to access and share SFM information, e.g., by attaching condition assessments or SFM documentation to building elements. The goal of this study is to develop a workflow for creating an SFM-enhanced BIM model for existing buildings. Revit and BUILDER SMS are the BIM and SFM software studied, respectively.

A workflow previously used by the authors to create Revit models and populate BUILDER SMS databases for existing buildings is summarized in Figure 1. A BIM team uses 3D laser scans to produce a point cloud of the facility and, ultimately, a BIM model. A BUILDER team inventories all building components and makes condition assessments. To populate an online BUILDER SMS database, a BUILDER Remote Entry Database (BRED) file is exported from the program, populated with facility data from the inventory using BuilderRED, and imported back into the online database. While these processes are performed for the same building, the workflow does not integrate the BIM model and SFM data, thus it does not produce an SFM-enhanced BIM model.

The research questions addressed by this project are:

1. What is the best workflow for creating an SFM-enhanced BIM model for an existing building using Revit and BUILDER SMS?

2. What applications will facility managers value in the resulting SFM-enhanced BIM model?

The scope of this study is limited to transferring BUILDER SMS (SFM) data to Revit (BIM) and evaluating the resulting SFM-enhanced BIM Model. The enhancements of the Revit model considered in this research are limited to data available in BUILDER SMS. 


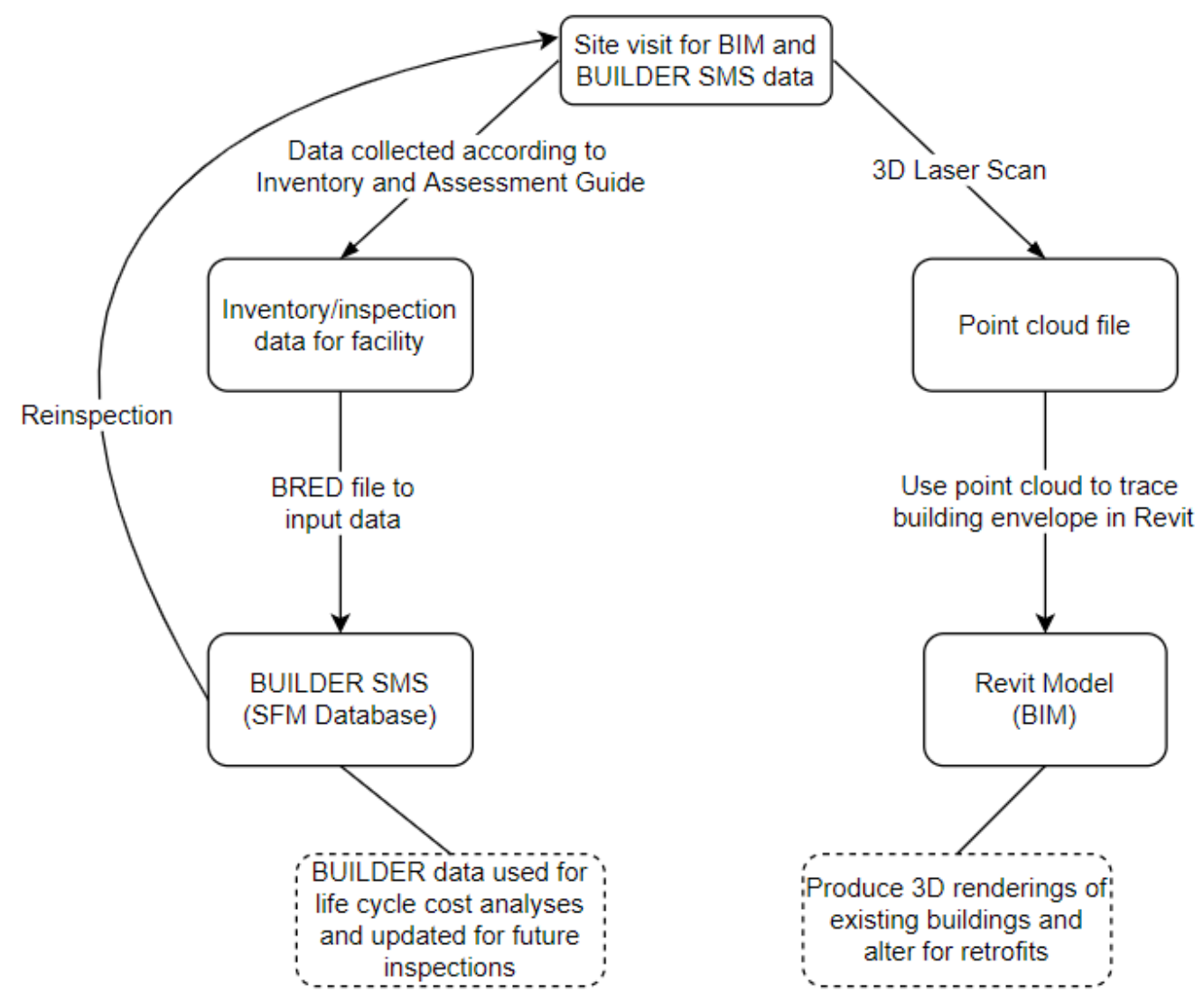

Figure 1. Existing workflow for Revit model and BUILDER SMS database.

\section{Background}

The overall life cycle cost of a building is largely influenced by the operations and maintenance (O\&M) phase [23]. Lack of interoperability among different software applications can be costly, with two-thirds of interoperability costs associated with the O\&M phase [24]. Building information modeling should be implemented with this issue in mind to ensure a smooth, logical transition from design and construction to facility management. Ideally, a BIM model holds essential information for different stakeholders, enables a seamless transfer through multiple phases, and provides a reliable database for facility managers to retrieve and analyze information [6].

One of the many applications of BIM is enhancing FM or SFM. Previous studies and industry implementation have identified benefits to integrating BIM with FM. A BIM model with adequate information for FM can be useful for: commissioning and closeout; quality control and assurance; energy management; maintenance and repair; and space management [25].

In a review of BIM for sustainability, Chong, Lee, and Wang [26] found that real time FM-enabled BIM systems can help eliminate inefficiencies in existing buildings. Facility owners seeking greater energy efficiency can use BIM with sustainable design principles when retrofitting a building [27]. Another strength of facility management integrated with BIM is the visualization capabilities of a BIM model that includes facility data. In a study focused on BIM-enabled facilities management, $86 \%$ of BIM users who responded to the survey submitted "Visualization and marketing" as a potential application area [25]. Visualization gives FM personnel the ability to perform conceptual analyses and makes it easy to prepare presentations of the building. Visualization capabilities can save time for corrective maintenance because faulty components can be located easily [28]. Other application areas for FM-enabled BIM include locating building components, facilitating real-time data access, checking maintainability, updating digital assets, space management and controlling energy usage [25]. 
While the majority of past research for building information modeling has been focused on the design phase, some recent research includes facility management issues such as maintenance and refurbishment during the operation phase [9]. Several studies have focused on ways FM-enabled BIM can be used in specific scenarios. Lu et al. [23] compared the traditional O\&M and BIM-assisted processes for daily O\&M, emergency O\&M, and statutory inspection. One major limitation of the traditional process was scattered information. In the traditional process, some tasks were repeated by different staff, which made information acquisition more time-consuming. Another issue with the traditional process was the difficulty in searching and verifying the correct facility information among different files or records. This was due to facility data being stored in spreadsheets and hardcopy formats, while floor plans were stored as their original hardcopies or 2D CAD drawing files.

Pishdad-Bozorgi et al. [6] studied the creation of an FM-enabled BIM during the design and construction phase. While this pilot study was successful in implementing FM-enabled BIM, there were challenges and limitations. The O\&M documentation was not fully integrated and had to be manually entered directly into the facility management software database. It was suggested that O\&M documentation could be linked to BIM objects with a URL code. This case study also had issues with data validation due to incompatibility between the handover documentation from the construction phase and the facility management software.

Table 1 summarizes major concerns with integrating BIM and FM systems that have been identified in the literature. The research described here attempted to create an SFMenhanced BIM model taking into consideration the issues described above and in Table 1.

Table 1. Concerns with integrating BIM and FM systems identified from past research.

\begin{tabular}{cc}
\hline Concern & Sources \\
\hline Data incompatibility between BIM and FM software & {$[3,25,29-35]$} \\
\hline $\begin{array}{c}\text { Lack of appropriate FM information/maintaining quality } \\
\text { of information }\end{array}$ & {$[6,24,29-31,33,36,37]$} \\
\hline Sufficient BIM/FM knowledge of stakeholders & {$[4,28,29,35,38,39]$} \\
\hline Cyber security/data ownership & {$[9,25,35]$} \\
\hline
\end{tabular}

\section{Methods and Materials}

This research focused on integrating a basic BIM model with SFM data to create an SFM-enhanced BIM model. While the existing workflow (Figure 1) does not create an SFM-enhanced BIM model, it does create a basic BIM model and populate a separate SFM database. It can serve as a starting point for an integration workflow. The basic BIM model was created using a scan-to-BIM workflow: Autodesk ReCap Version 5.1.0.19 [40] to assemble a point cloud file for the building and Autodesk Revit 2018, Version 18.3.3.18 [17], to create a 3D building model based on visible (and traceable) surfaces in the point cloud. The BIM model included the envelope of the superstructure, the interior walls, and exposed mechanical, electrical, and plumbing (MEP) systems. The SFM database used was BUILDER SMS [8], a web-based application that stores and tracks the condition of building components. It is populated or updated using data from an on-site inventory.

Two data transfer methods were developed to integrate the BIM model with SFM data. The methods were evaluated using a case study at an existing facility. Once the case study was complete, an integration workflow was proposed and the resulting SFM-enhanced BIM model evaluated by a focus group consisting of appropriate FM staff. Evaluations were qualitative and quantitative in nature. 


\subsection{Case Study}

The sponsor of this research was the New Jersey Department of Military and Veterans Affairs (NJDMAVA). NJDMAVA operates facilities with over two-million square feet of floor area (185,000 square meters). Over the past four years, the authors have supervised the completion of Revit models and BUILDER SMS databases at 16 and 98 NJDMAVA buildings, respectively. However, the BIM models were created without considering potential integration with BUILDER SMS. The building used for the case study presented here, referred to as Building $\mathrm{A}$, was chosen because it represents a typical building for the sponsor. The building is a 10,000 to 20,000 square foot facility constructed in the $1980^{\prime} \mathrm{s}$ with between 20 and 30 rooms (Figure 2). A Revit model (Figure 3) was completed in 2016 using the scan-to-BIM workflow described previously. A BUILDER SMS database was completed in 2018 following the BUILDER SMS Inventory and Assessment Guide [41]. Due to security concerns, various items of information are left vague and portions of some figures obscured with black boxes in accordance with NJDMAVA policy [42].

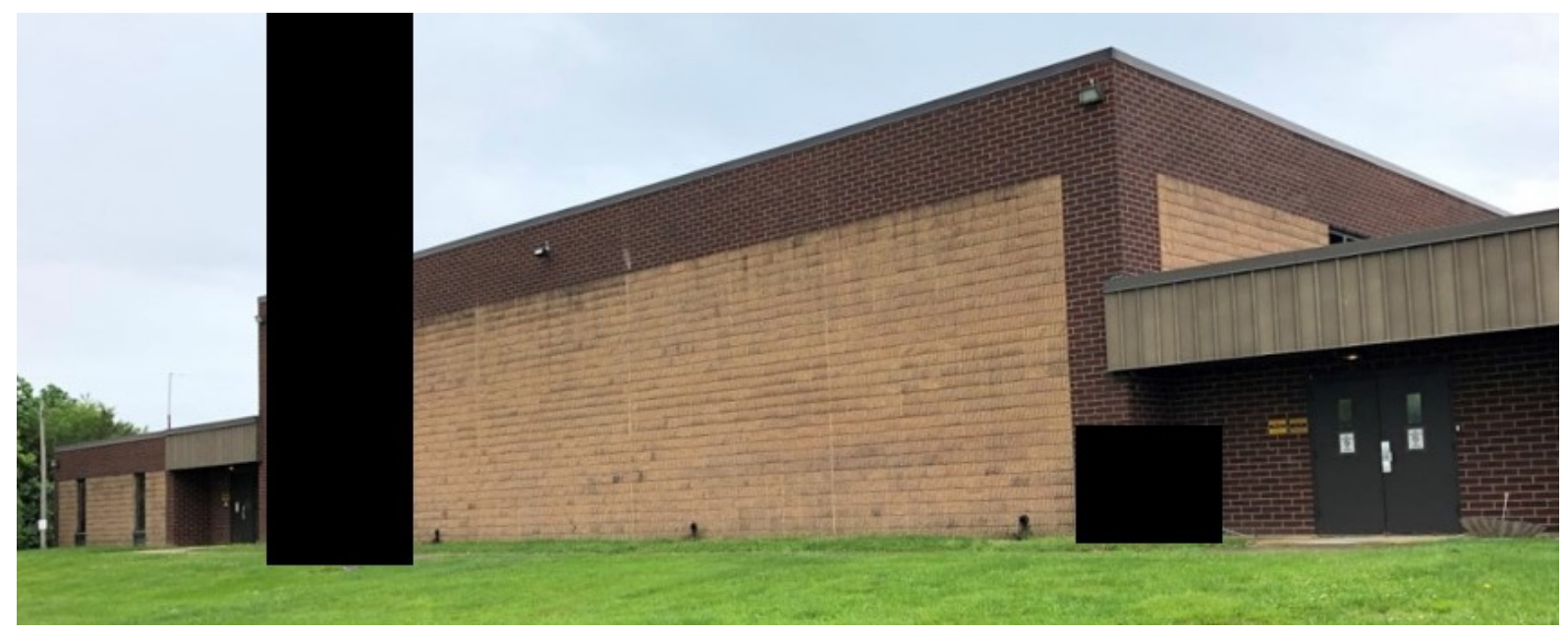

Figure 2. Photograph of Building A.

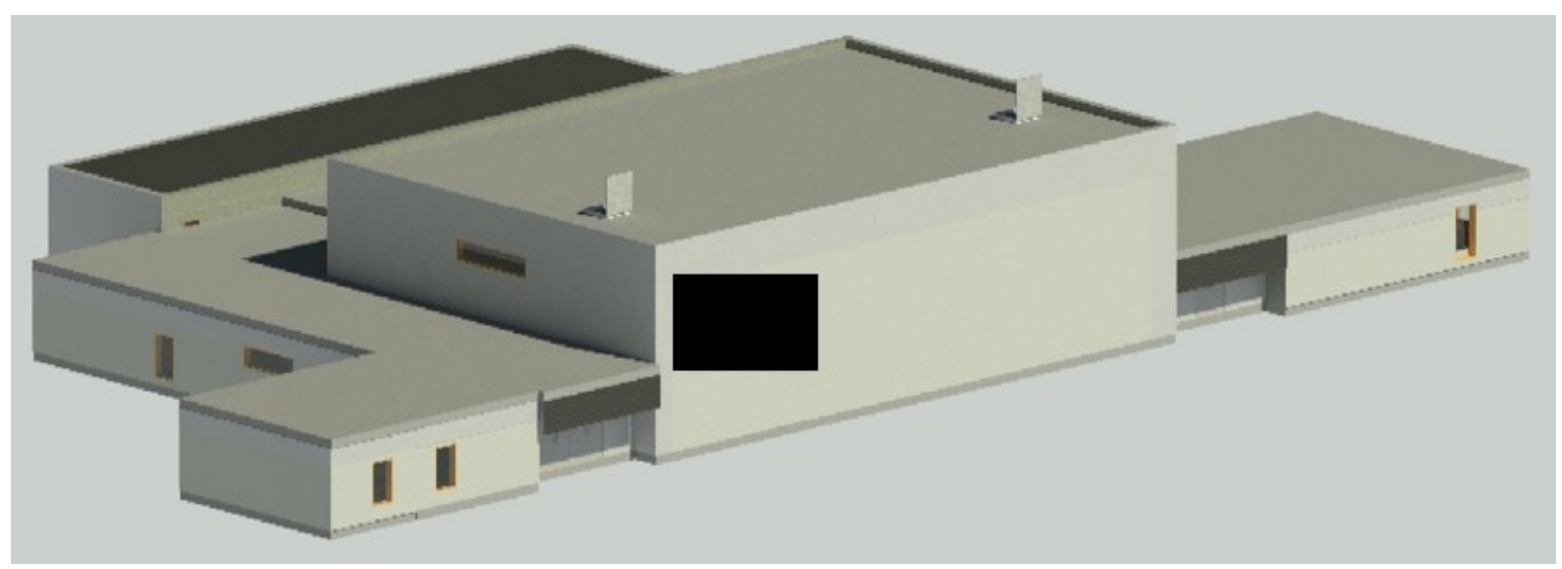

Figure 3. Revit Model of Building A.

\subsection{Data Structure Compatibility}

Comparing the data structures of Building A's existing Revit model and BUILDER SMS database revealed incompatibilities. Building A's Revit model had to be altered to be compatible with BUILDER SMS. Issues and workarounds are shown in Table 2. Future BIM models can be created from scratch with a compatible data structure. 
Table 2. Potential conflicts between Revit BIM and BUILDER SMS datasets.

\begin{tabular}{|c|c|c|c|}
\hline Issue & BIM (Revit) & BUILDER SMS & Resolution \\
\hline $\begin{array}{l}\text { Building } \\
\text { directional } \\
\text { referencing }\end{array}$ & $\begin{array}{l}\text { Adjusted in project settings by } \\
\text { setting Project North and True } \\
\text { North }\end{array}$ & $\begin{array}{l}\text { During data entry, certain } \\
\text { components are associated with } \\
\text { relative position in the facility } \\
\text { ("East Wall Windows") }\end{array}$ & $\begin{array}{l}\text { Cardinal directions must be } \\
\text { accurate to the actual facility } \\
\text { in both models to ensure } \\
\text { compatibility and user } \\
\text { comprehension }\end{array}$ \\
\hline $\begin{array}{c}\text { Objects with } \\
\text { quantities }\end{array}$ & $\begin{array}{c}\text { Each individual object is } \\
\text { modelled as an instance, each } \\
\text { with its own unique properties } \\
\text { and identities }\end{array}$ & $\begin{array}{l}\text { Windows, doors, fixtures, etc. } \\
\text { are modelled as groups with a } \\
\text { quantity. Their data applies to } \\
\text { all of the components in that } \\
\text { group }\end{array}$ & $\begin{array}{l}\text { Each instance in Revit can } \\
\text { have the same parameter } \\
\text { values as the group in } \\
\text { BUILDER SMS, so each } \\
\text { individual object in Revit will } \\
\text { have the same properties as } \\
\text { others in the grouping }\end{array}$ \\
\hline Surface finishes & $\begin{array}{l}\text { Most models were previously } \\
\text { made with walls / roofs/floors } \\
\text { modelled as a single instance } \\
\text { with multiple layers }\end{array}$ & $\begin{array}{l}\text { Floor construction and floor } \\
\text { covering are two separate } \\
\text { entities, each with their own } \\
\text { identifying data }\end{array}$ & $\begin{array}{l}\text { Add very thin wall/roof/floor } \\
\text { coverings to each surface in } \\
\text { BIM model }\end{array}$ \\
\hline $\begin{array}{l}\text { Window } \\
\text { groupings }\end{array}$ & $\begin{array}{l}\text { Window models loaded in as } \\
\text { single instance with multiple } \\
\text { panels }\end{array}$ & $\begin{array}{l}\text { Window sections with multiple } \\
\text { panels in BUILDER are counted } \\
\text { as quantities with the number of } \\
\text { panels }\end{array}$ & $\begin{array}{l}\text { Window instance in Revit is } \\
\text { given the data for the } \\
\text { component in BUILDER, with } \\
\text { the number of panels given by } \\
\text { the window type }\end{array}$ \\
\hline Wall/partitions & $\begin{array}{c}\text { Most models were previously } \\
\text { made with walls modelled as } \\
\text { a single instance with multiple } \\
\text { layers }\end{array}$ & $\begin{array}{l}\text { Walls have data records for the } \\
\text { exterior wall, interior partition, } \\
\text { and surface finish }\end{array}$ & $\begin{array}{l}\text { Future BIM models would } \\
\text { need separate exterior and } \\
\text { interior layers to allow for } \\
\text { walls to be referenced }\end{array}$ \\
\hline
\end{tabular}

Two parameter groups were added to Building A's Revit model. The BUILDER SMS "Component Section" and "Section Details" groups were applied to all Revit elements. The Component Section parameter group applied to a Revit model is shown in Figure 4. It contains the majority of relevant information for each BUILDER SMS component, including a unique identifier (SEC_ID) generated by BUILDER SMS.

\subsection{Data Transfer Methods and Workflow}

Once data compatibility is ensured data can be transferred. Data transfer method 1 involves manually inputting BUILDER SMS data directly into the Revit model. Data for each BUILDER SMS component are entered into the corresponding Revit element. This method does not require staff expertise in automated data transfer.

Data transfer method 2 involves manually entering only the unique BUILDER SMS identifier of each component into the corresponding Revit element. The remaining data are transferred using three files: a BUILDER SMS BRED file, a Revit model DB Link file, and an intermediate database created using Microsoft Access [43]. The BRED file has already been introduced. BRED files are compatible with Microsoft Access and can be used to export data from or import data into an online BUILDER SMS database. DB Link is an Autodesk add-in used to export data from or import data into a Revit model. The resulting file is compatible with Microsoft Access, Microsoft Excel [44], or ODBC databases. The intermediate database is used to transfer data between the DB Link and BRED files while ensuring they remain compatible with Revit and BUILDER SMS, respectively. Microsoft Access Select Queries are used to connect the intermediate database to the DB Link and BRED files. The data can then be easily transferred in the form of a single table for each Revit category (i.e., "Walls", "Doors", "Floors", etc.) in the building. 


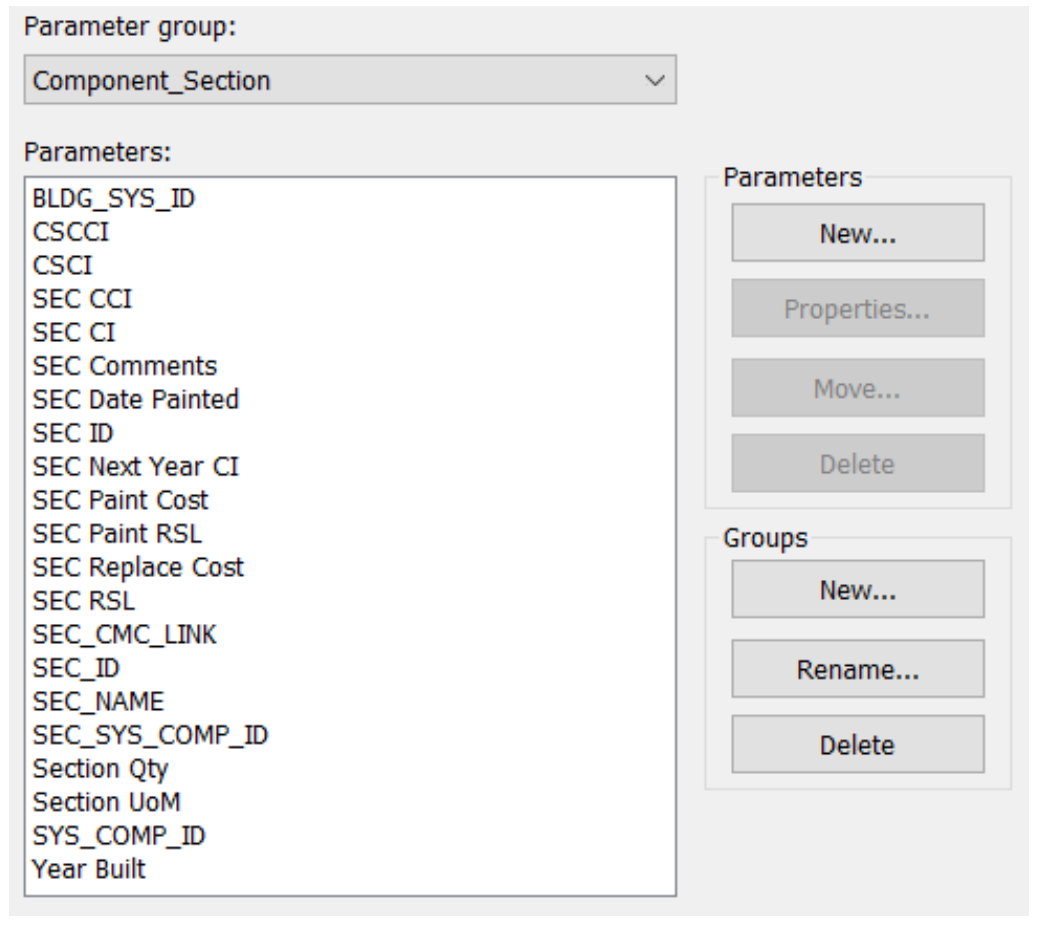

Figure 4. Component Section Parameter Group in the Revit model.

It is necessary to understand Revit and BUILDER SMS data structures to create a connection between the two platforms. A BRED file exported from BUILDER SMS has relationships that help link the data hierarchy (Figure 5) as well as create Select Queries to support the functionality of the database. The relationships rely on a primary key to match datasets such that the related data parameters are arranged correctly. For the intermediate database to work, the BUILDER SMS unique identifier SEC_ID was added to the Revit model to link corresponding Revit elements and BUILDER SMS components and to allow relationships to be created for automatic data transfer. Once the components in BUILDER SMS are associated with their corresponding Revit element via their SEC_ID value, the remaining data parameters can be transferred between Building A's BRED and DB Link files via the intermediate database.

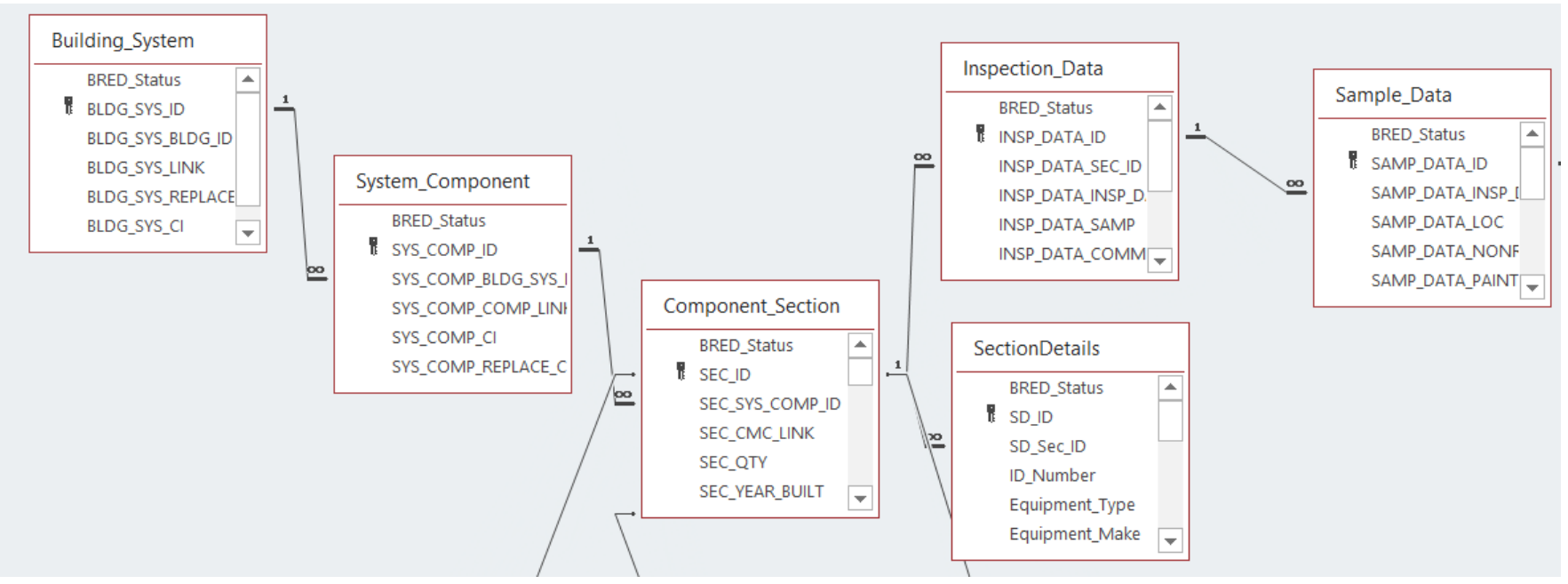

Figure 5. Table relationships inherent in the BRED database. 
A test run was performed for method 2 using a simple hypothetical Revit model to ensure method feasibility. The simple model only included a building envelope. The initial test involved an export of Revit data to Excel using DB Link. Data values were then altered in the Excel file and imported back into Revit using DB Link again. This confirmed that the data could be edited outside of the BIM authoring software.

To further evaluate data transfer using the simple hypothetical Revit model, parameter values were altered and transferred between the DB Link and BRED files using the intermediate database. The DB Link and BRED files were then imported back into Revit and BUILDER SMS, respectively. Changes were correctly reflected in the DB Link file and in Revit which, upon import or an error, clearly identified formatting or structural issues which could then be corrected. Changes were correctly reflected in the BRED file but, occasionally, changes were ignored during import into BUILDER SMS. The root of the problem was not determined but could cause errors in the future if data transfer from Revit to BUILDER SMS is desired. Here, only transfer from BUILDER SMS to BIM was intended.

An online BUILDER SMS database uses formulas to calculate certain values, e.g., Condition Indices. The formulas are not included in BRED files; thus, calculated values are only automatically updated in the online database. For example, changing the "Year Installed" value in a BRED file does not alter the related Condition Index. The change only occurs in the online BUILDER SMS database, once the updated BRED file is imported. This is not necessarily a problem, but something that can confuse inexperienced users.

Once method 2 was tested on the simple hypothetical scenario, BRED and DB Link files were exported for Building $A$ and an intermediate database created and used to transfer data from the BRED file to the DB Link file. The DB Link file was then used to import BUILDER SMS data into the Revit model. The work flow for method 2 is shown in Figure 6. Changes relative to the original workflow (Figure 1) are shown in red.

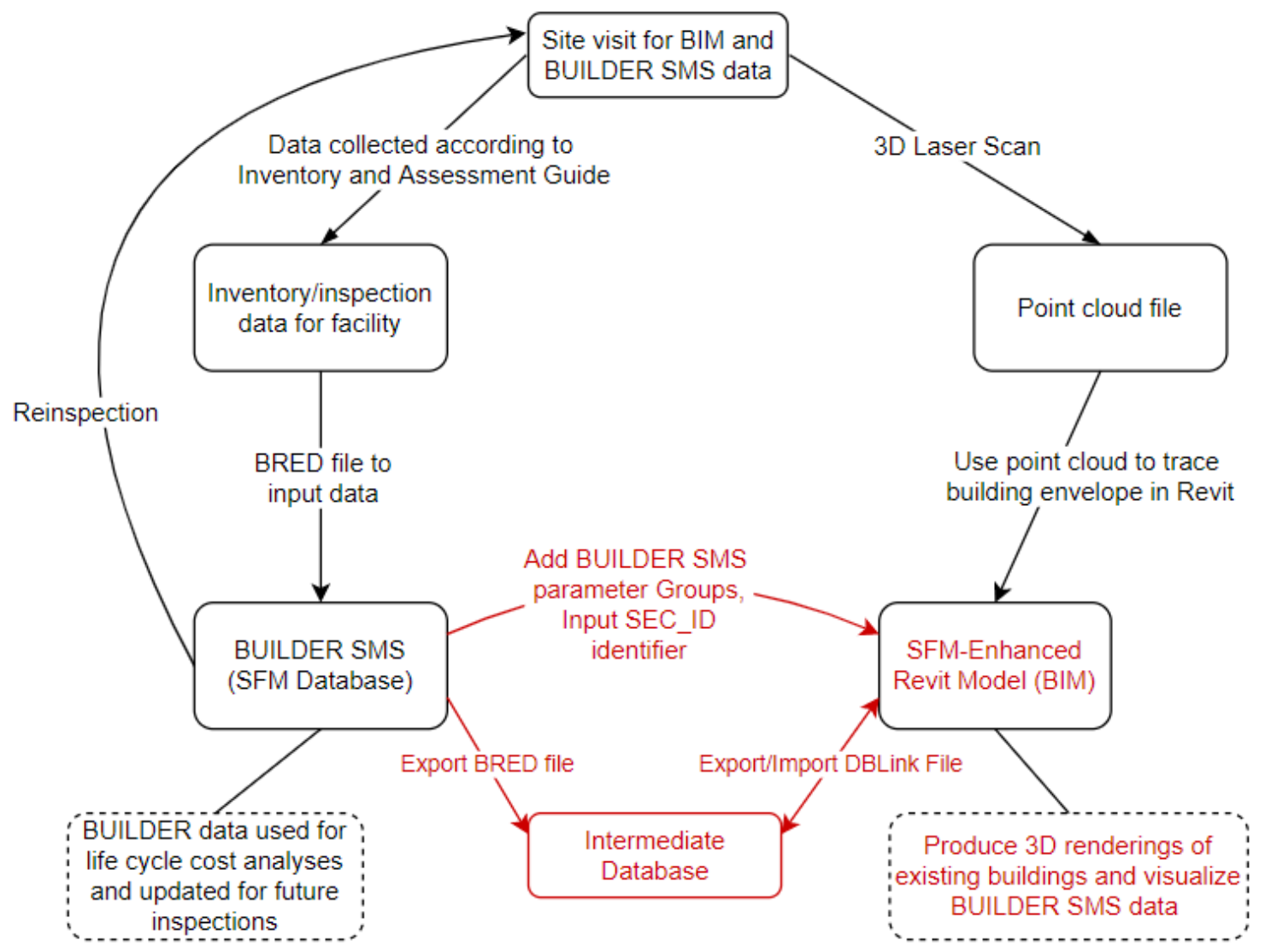

Figure 6. Integration workflow for Revit and BUILDER SMS for an existing building. 
When data transfer methods 1 and 2 were applied to Building A, observations and time-to-completion were recorded. All conflicts or errors observed were used to compare and improve the methods. The two resulting SFM-enhanced BIM models were also compared to assess the reliability of the data transfer methods. Each model's data were exported to Microsoft Excel (using DB Link) and conditional formatting used to find any differences. Accurate data transfer via each method would result in identical models. Finally, a new integration workflow was proposed for populating BUILDER SMS and creating an SFM-enhanced BIM model in Revit.

\subsection{Focus Group}

A focus group of NJDMAVA FM staff was used to evaluate the SFM-enhanced BIM model created for Building A, using Autodesk Revit and Autodesk Viewer [45] to view and interact with the model. The focus group discussion was recorded and reviewed. A survey was used to assess staff experience and evaluate various scenarios for using the SFM-enhanced BIM model (see Supplementary Materials). Some survey responses used a five-point Likert scale, similar to previous assessments [29,32,46].

\section{Results}

The results of the data transfer evaluation, the focus group discussion, and the focus group questionnaire are presented in this section.

\subsection{Data Transfer}

Data transfer method 1 was more labor-intensive because each Revit element had to be selected and populated with BUILDER SMS data, except for groupings where multiple elements in the Revit model were associated with the same BUILDER information. Figure 7 shows a breakdown of time expenditure to input data for each Level 2 UNIFORMAT II category [47].

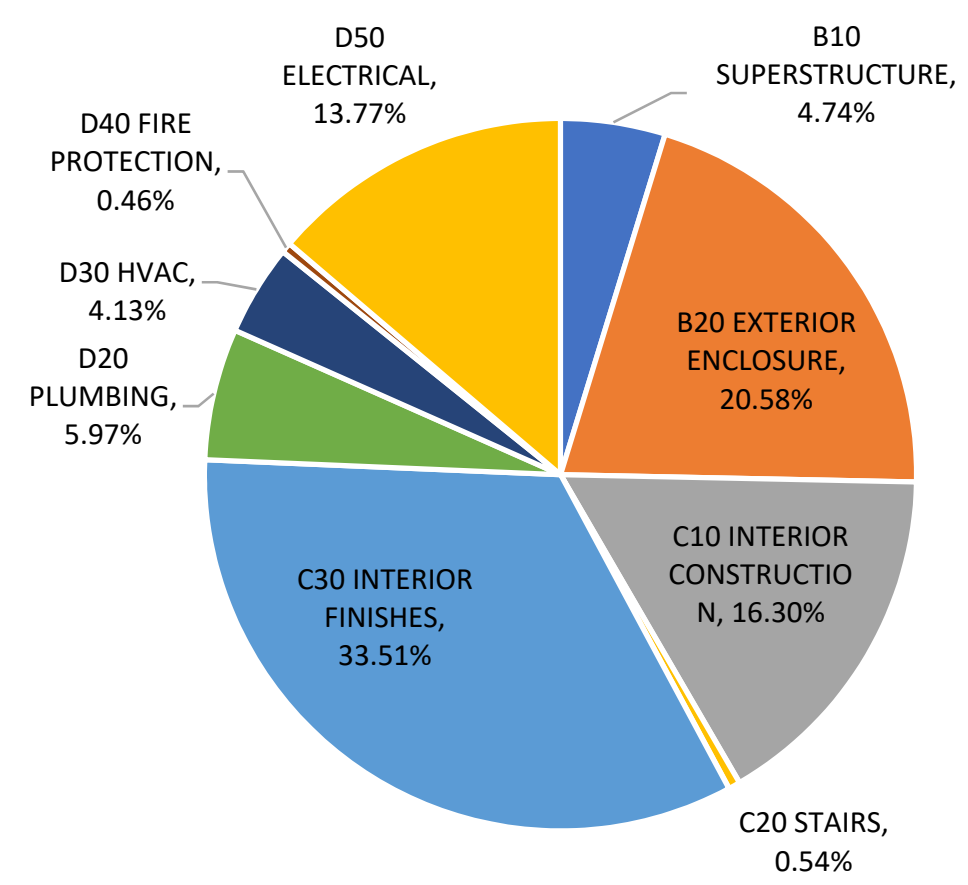

Figure 7. Data entry by asset management group for data transfer method 1 (\% time).

The total time to complete the transfer was $218 \mathrm{~min}$. Each building element was populated with BUILDER SMS data in $1.21 \mathrm{~min}$ on average. A positive aspect of the method is its simplicity. It requires the least staff training. Populating each Revit element with the BUILDER SMS component data also creates an opportunity to conduct a quality 
check on the BUILDER SMS data, if desired. There are several drawbacks to method 1. First, the method is slow and tedious, which could unacceptably consume staff time and lead to errors. These issues are compounded if this method is to be used at multiple facilities and/or with repeated updates of BUILDER SMS that then need to be transferred to the Revit model. Familiarity with the Revit model and the BUILDER database is required for data transfer with this method to be completed in a timely manner. Finding the right elements in the model and referencing them in the BUILDER SMS database simultaneously is difficult if the user is not familiar with each. Method 1 would take even more time for a larger and more complex facility.

Data transfer method 2 was less labor-intensive. Only the SEC_ID identifier values had to be manually entered into Revit elements. The manual step to link the components with the identifier was completed in $117 \mathrm{~min}$, which included locating each element in Revit and its associated component in BUILDER SMS, and entering the identifier into Revit. While this stage was fairly straightforward, it was still tedious and appears to be difficult to automate. The test was done with an exported spreadsheet from BUILDER SMS displayed simultaneously with the Revit model.

The time spent manually entering SEC_ID values into BIM model elements could have been reduced with better knowledge of and more consistent data representation in each piece of software, similar to method 1. The time to input the BUILDER SMS identifiers into the model increases with the size and complexity of the building, also similar to method 1. However, the risk of data entry error is reduced compared to method 1, as method 2 requires significantly less manual data entry per building element.

The next part of method 2 was to use Microsoft Access to set up an intermediate database to access data from both sources and prepare it for transfer. Select Queries made BUILDER SMS parameters in the BRED file and corresponding parameters from the DB Link file visible in the same view. This method takes advantage of having the tables linked by the SEC_ID of each component/element, which joins the two tables together, e.g., the Revit table for the "Walls" category can be joined to the BRED file's "Component Section" table (Figure 8).

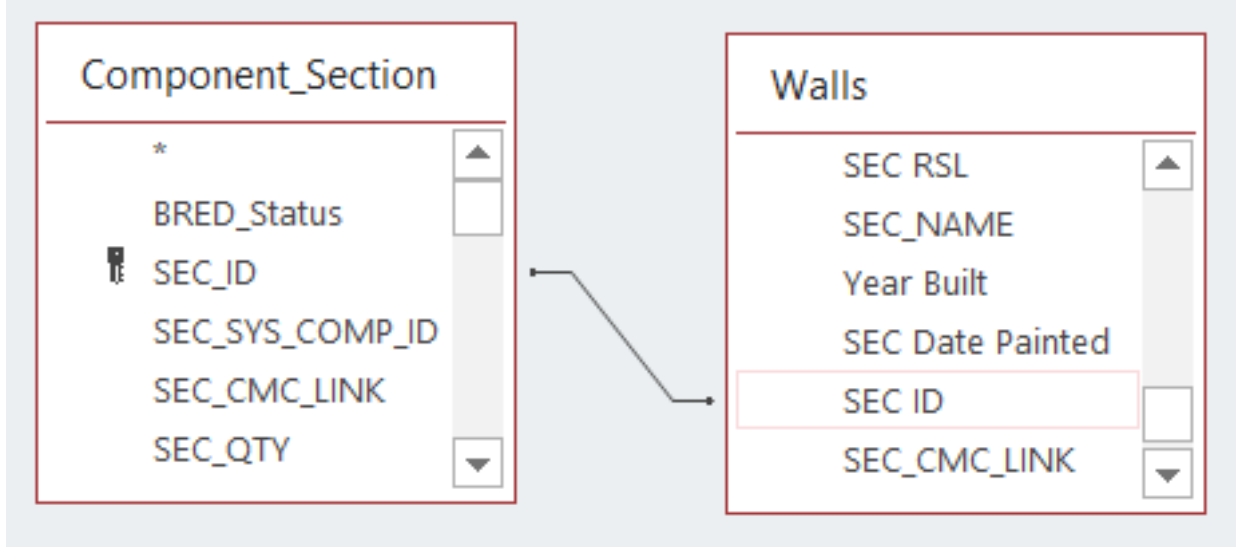

Figure 8. Query design showing joined tables in the intermediate database.

Once one Select Query was created, it could be copied and the table name modified to create queries for each Revit category. The "Component Section" Select Queries took $20 \mathrm{~min}$ to set up for this facility. The "Section Details" Select Queries took $11 \mathrm{~min}$. Data are transferred by running the Select Queries. Microsoft Access took 12 min to transfer BUILDER SMS data from the BRED file to the DB Link file. The updated data were then imported into Revit using DB Link, which took less than a minute. The DB Link log showed no data transfer errors.

Method 2 is faster than method 1 . The time for the first completion of this method was $161 \mathrm{~min}$, with the breakdown shown in Figure 9. 


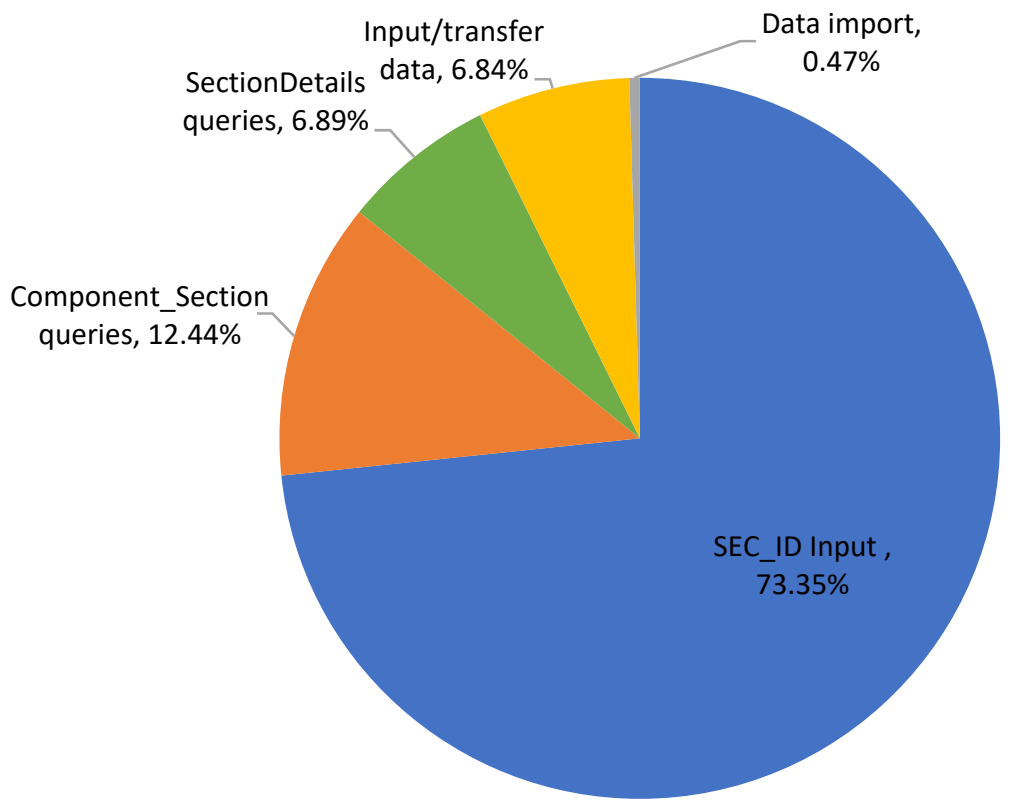

Figure 9. Percentage distribution of time to complete each stage for method 2 evaluation.

Method 2 is more efficient than method 1 for a one-time transfer, but much more efficient when multiple updates are planned. Method 2 was completed initially at an average of $0.89 \mathrm{~min}$ per component. The majority of the time was spent inputting the BUILDER SEC_ID values, which only needs to be done once per facility. For future updates, the process only consists of the "Input/transfer data" and "Data import" phases, $12 \mathrm{~min}$ in total and only $4 \mathrm{~s}$ per component. So, the process took 161 versus 218 min the first time for Building $\mathrm{A}$, then $12 \mathrm{~min}$ versus $218 \mathrm{~min}$ after that. A repeat operator should be able to complete method 1 for Building A in less than 218 min after the first attempt, but they will never approach $12 \mathrm{~min}$.

Another advantage of method 2 is that once this process is set up, it is easy for less experienced staff to complete the data transfer, as knowledge of the building is only important for the initial setup. Interpreting the data in a spreadsheet view is fairly easy to repeat as additional data updates are needed. A drawback of this method is the effort and expertise needed to setup the intermediate database and the troubleshooting needed if there are errors in the structure of the database. The strengths and weaknesses of the two methods are summarized in Table 3.

After the data transfer from BUILDER SMS to BIM was completed for methods 1 and 2 , the data were compared to identify any differences. DB Link was used to export each BIM model's data into Excel. No discrepancies between the method 1 and method 2 BIM worksheets were found. While it is possible for errors to occur during the data transfer, this case study showed that both methods can transfer data between Revit and BUILDER SMS and yield the same result. It is unlikely this would occur if there had been data transfer errors. This demonstrates the feasibility of method 1, especially if only one data transfer is considered and/or the skills required by method 2 have yet to be acquired.

Based upon the observations made while transferring data, alterations and improvements can improve quality control and the efficiency of future data transfers. The identified areas for improvements include:

1. Coordination between Revit model authors and BUILDER SMS inventory staff to ensure data compatibility of future models without requiring modifications;

2. Input of BUILDER SMS component identifiers simultaneously with Revit model creation;

3. Development of fully integrated Revit-BUILDER SMS workflow for data transfer/updates. 
Table 3. Summary of comparison for data transfer methods.

\begin{tabular}{cc}
\hline Strengths & Weaknesses \\
\hline $\begin{array}{c}\text { Most intuitive method since it resembles simple } \\
\text { data entry }\end{array}$ & $\begin{array}{c}\text { Method 1 (manual) } \\
\text { Slowest method for frequent updates of databases }\end{array}$ \\
$\begin{array}{c}\text { Little initial setup required; data transfer is the } \\
\text { majority of time spent }\end{array}$ & $\begin{array}{c}\text { Possibility of human error due to large amounts of individual data } \\
\text { points being inputted manually }\end{array}$ \\
\hline $\begin{array}{c}\text { Easier to interpret data in spreadsheet-like view } \\
\text { Transfer /import process is faster than previous } \\
\text { method }\end{array}$ & $\begin{array}{c}\text { Setup process is slowed down by manually inputting BUILDER } \\
\text { SMS identifiers and setting up Access queries for multiple facilities } \\
\text { Requires both Revit and BRED database exports to be accurate and } \\
\text { Ideal for frequent updates }\end{array}$ \\
\hline
\end{tabular}

A previous study made the case that future research on BIM/FM integration should develop new BIM/FM workflows [6]. The research presented here did just that. A new workflow for collecting and developing data for existing buildings and integrating Revit and BUILDER SMS is given in Figure 6. It improves upon Figure 1 by creating an SFMenhanced BIM model using data transfer method 2. It illustrates the relationship between Revit and BUILDER SMS and how their datasets are connected. The figure can also provide insight for creating SFM-enhanced BIM models for existing buildings using other BIM or SFM software.

\subsection{Focus Group}

A focus group was used to evaluate the SFM-enhanced BIM model. PishdadBozorgi et al. [6] recommend evaluating the value of BIM/FM integration schemes. The focus group was comprised of five NJDMAVA staff members with opportunities to use an SFM-enhanced BIM model. Each focus group member completed an initial questionnaire. Table 4 summarizes each focus group member's title, responsibilities and self-assessed familiarity with BIM and BUILDER SMS based on a five-point Likert scale.

Table 4. Focus group members by title and responsibilities.

\begin{tabular}{cccc}
\hline Title & Responsibilities & $\begin{array}{c}\text { BIM } \\
\text { Familiarity }\end{array}$ & $\begin{array}{c}\text { BUILDER SMS } \\
\text { Familiarity }\end{array}$ \\
\hline Facilities Manager & $\begin{array}{c}\text { Enter/process work orders. Ensure } \\
\text { buildings/facilities are maintained and fully } \\
\text { functional }\end{array}$ & Slightly & Slightly \\
\hline $\begin{array}{c}\text { Installation Status Program } \\
\text { Manager }\end{array}$ & Create installation status reports & Somewhat & Very \\
\hline $\begin{array}{c}\text { Facility Management Bureau } \\
\text { Chief }\end{array}$ & $\begin{array}{c}\text { Oversee facility maintenance for Army } \\
\text { National Guard Buildings in the state of New } \\
\text { Jersey }\end{array}$ & Somewhat & Slightly \\
\hline $\begin{array}{c}\text { Responsible for facilitating repair of NJ } \\
\text { National Guard Armories and buildings. } \\
\text { Process/add/track work orders put into } \\
\text { Facility Dude (software) }\end{array}$ & Not familiar & Not familiar \\
\hline Specialist & $\begin{array}{c}\text { Coordinate Building Energy Audits. Facility } \\
\text { electrical/gas/oil water billing review and } \\
\text { reporting. Energy-efficient project } \\
\text { procurement. }\end{array}$ & Slightly & Slightly \\
\hline
\end{tabular}


The focus group had an overall low familiarity with both building information modeling (BIM) and facility management via BUILDER SMS. BUILDER SMS is in the middle of a five-year implementation at NJDMAVA. However, there was high potential for the group to use SFM-enhanced BIM.

The discussion began with a brief overview of Revit and BUILDER SMS because of the varying levels of expertise among the group. They were able to see data as they are presented in the online database for BUILDER SMS as well as how they are currently entered using BRED files. BUILDER SMS fixed and calculated data were shown, e.g., Year Built, Remaining Service Life, Condition Index (CI), etc. This transitioned into displaying BUILDER SMS data in the SFM-enhanced BIM model. The first demonstration involved showing Building A in Autodesk Viewer (Figure 10), a web-based 3D viewer compatible with Revit BIM models. Autodesk Viewer is an online file viewer compatible with several design and construction file formats that allows for viewing and sharing of documents. It was used to show a 3D rendering of the building and to display its accessibility and ease of use. This demonstration showed how a BIM model can be easily accessible to a variety of staff members and the usefulness of its first-person capabilities. Some of the features demonstrated included walking through a building and selecting instances in the view to see properties and associated BUILDER SMS data. One group member suggested this could be helpful in planning future site visits by allowing individuals to familiarize themselves with the building layout, view the layout and contents of particular rooms, or access BUILDER SMS data on a tablet while on site.

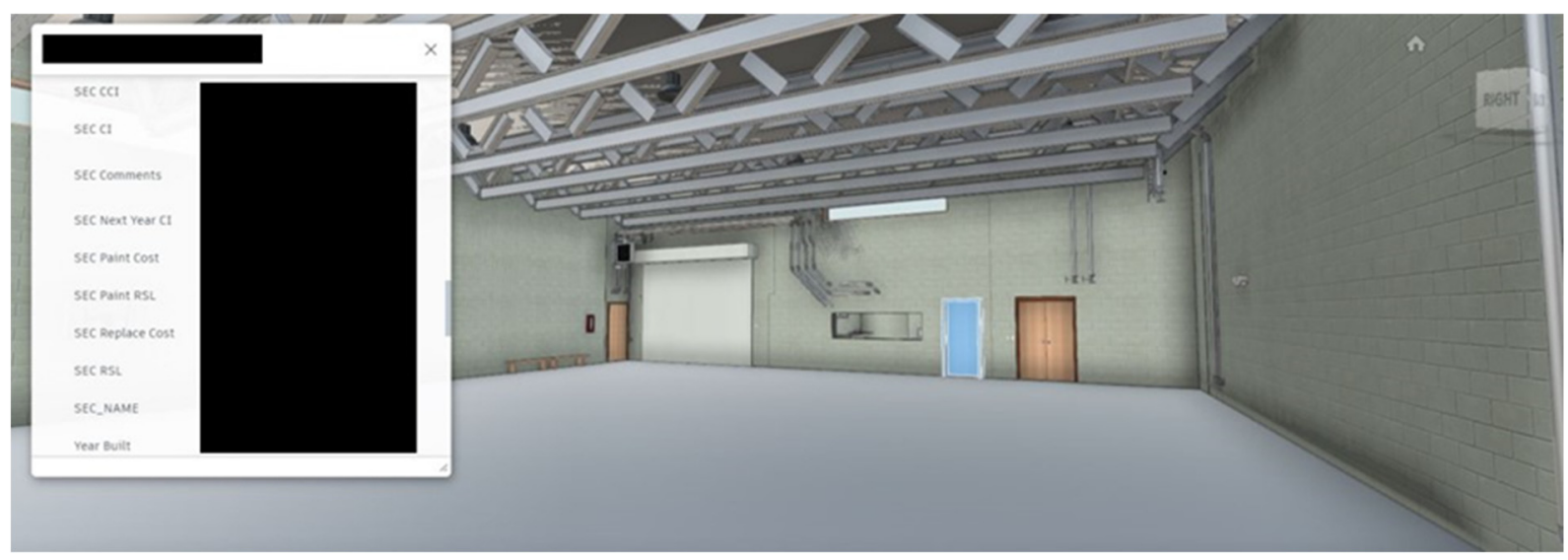

Figure 10. First-person view of Building A as shown in the focus group demo.

The next part of the demonstration involved showing other data visualization methods in a Revit model. One of the concepts demonstrated was the use of visual filters based on BUILDER SMS parameters. Since the color scale of the BUILDER SMS Condition Index is green, amber, or red, a visual filter based on the CI value was applied to the model to view the condition of the building. A 3D view with this filter applied for next year's CI is shown in Figure 11.

In addition to 3D model views, the BIM model can directly provide data-rich floor plan views. It was demonstrated that a side-by-side 2D view of Building A could be used to compare the current CI value with next year's projected CI according to BUILDER SMS, which visually shows expected degradations. One of the members noticed a difference in color between the two views of the model, demonstrating that a visual representation of the depreciation of building components can be useful for facility staff. The last part of this Revit demonstration was a prerecorded walkthrough of the building, with and without the visual filter applied. The idea was to show that a basic overview of the building's health can be shown if the walkthrough covers all rooms, or it can be used to give more specific information for a particular location in the building. 


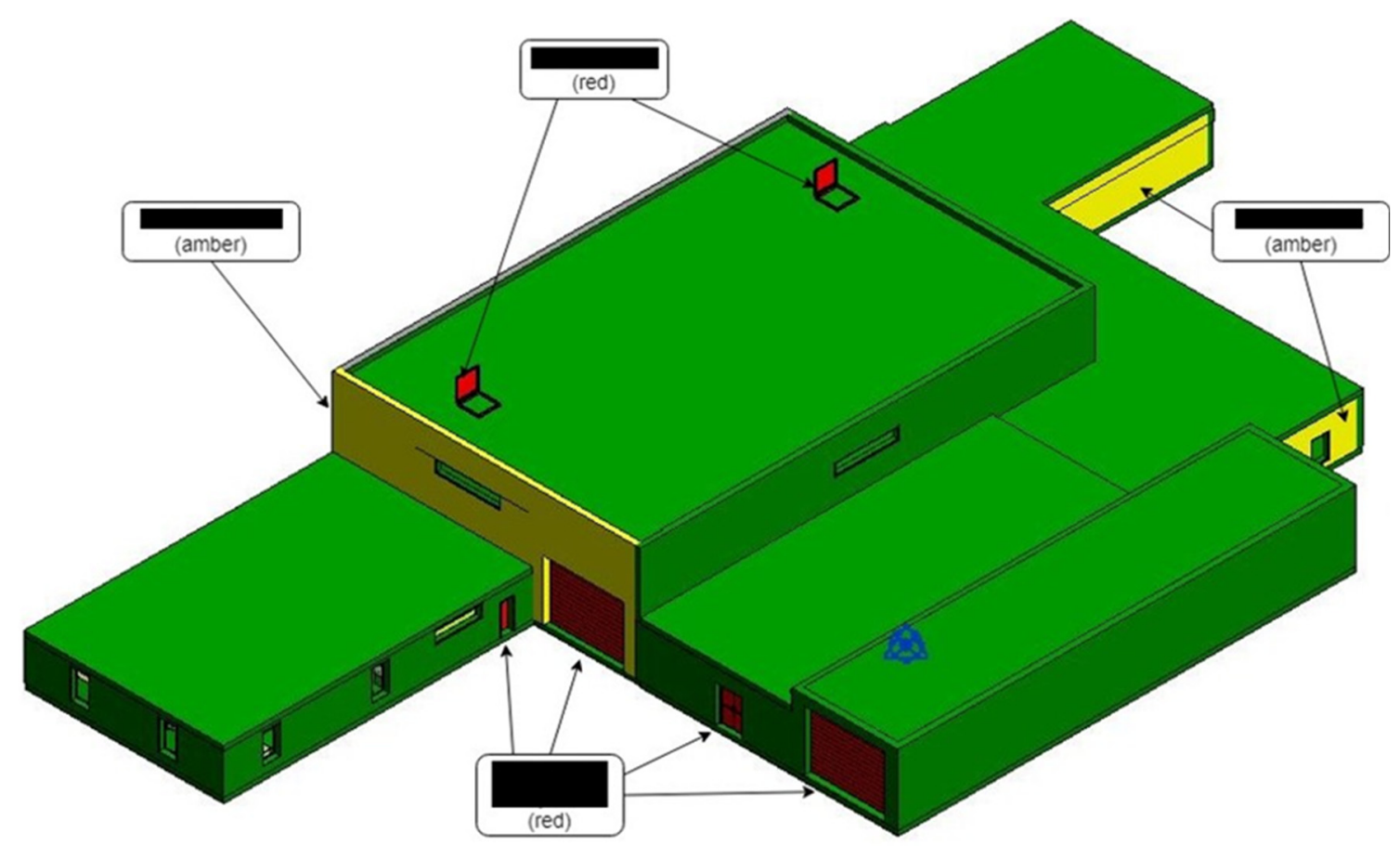

Figure 11. Demonstration of visual filter for Condition Index (CI) value of Building A.

A questionnaire was completed by all five staff members to gain insight on their reaction to the demonstration as well as to collect any feedback or suggestions they had for utilizing BUILDER SMS data displayed in BIM. Short answer questions allowed the group to share their opinions on how integrating Revit and BUILDER SMS could be valuable in different aspects of their work.

One of the questions prompted the focus group to consider how BIM could be used to improve preventative maintenance at their facilities. Their responses were unanimous in that they saw the use of BIM for displaying BUILDER SMS data as an improvement. One response stated that, "being able to quickly identify pieces of equipments's [sic] lifecycle or direct input assessment for current and future years gives a quick identification of what may fail". The visual aspect of BIM was seen as useful for "fast, visual review of components". After being shown the facility data in both the database format as well as in a BIM model, four out of five of the respondents expressed that they preferred the visual format of viewing data in BIM. The other respondent stated that they had no preference. They explained that the visual representation could allow them to "identify issues more quickly and with greater detail" and "more easily get a high-level overview of a facility". Finally, when asked if BIM should have a more significant role in assisting with their facility management, the group was unanimous in thinking that it should be used. One focus group member, a building management specialist, stated that using BIM and BUILDER SMS would allow for better cost-saving efforts and improved building assessments. These short answer questions resulted in positive feedback for Revit and BUILDER SMS separately and combined in an SFM-enhanced BIM model.

The last part of the questionnaire involved rating the perceived usefulness of BIM in assisting with various scenarios, followed by suggestions for other uses of BUILDER SMS data in BIM models. The rating was based on a Likert scale ranging from not all useful (1) to extremely useful (5). Table 5 shows the average ratings for each scenario sorted from highest to lowest based on the questionnaire. All of the scenarios were seen as very useful by the focus group members. The two highest rated scenarios were visual applications of the BIM model, which aligns with a previous study in which $86 \%$ of survey respondents saw "visualization and marketing" as a potential application area [25]. Scenarios 3 and 4 also align with the literature in that they can help save time when completing any maintenance tasks by expediting the process of locating faulty components [28]. While scenario 5 was 
still rated as a very useful application, it may have been rated lower because it was not something that would apply to the focus group members directly; rather it applies to the Revit model and BUILDER SMS database developers. However, the abilities to update digital assets [25] and assist with retrofit projects [35] are still beneficial to the client.

Table 5. Summary of results for BIM-BUILDER SMS scenario ratings.

\begin{tabular}{l}
\hline BIM-BUILDER SMS Scenario \\
\hline 1. Using BUILDER SMS parameters for visual filters to track patterns and problem areas in facilities. \\
2. BIM models can be viewed on a tablet/mobile device during future inspections or other site visits. \\
3. An outside vendor is given the BIM visualization of the facility to assist them with planning and \\
giving them information on the component(s). \\
4. A BIM model is connected to a work order system to track FM data in the facility and relate it to \\
rooms and spaces in the building. \\
5. Any retrofit projects of the building can be updated in both data locations if changed in either BIM or \\
BUILDER SMS.
\end{tabular}

The meeting was also used to identify additional scenarios where BIM and BUILDER SMS could be used. The focus group identified the following:

- The condition of building components based on the amount of funding;

- A phone application to show 3D BIM model including details of components;

- Incorporation of GIS (e.g., adding a weblink to the online browser viewer within the ArcGIS viewer currently used to have access to both floor plan and 3D views);

- $\quad$ Repair and maintenance staff ability to input real time data;

- Attaching photos/documents to equipment for inspector/technicians to have available while on site.

\section{Conclusions and Future Work}

As a case study, an SFM-enhanced BIM model was created from an existing Revit model and BUILDER SMS database. The experience was used to evaluate two data transfer methods and propose an integration workflow specific to that software combination (Figure 9), but which provides insights applicable for any BIM or SFM software combination. The resulting SFM-enhanced BIM model was evaluated using a focus group of FM professionals.

The integration of BIM and SFM was achieved by: (1) making alterations to the BIM model for increased compatibility with the SFM database, (2) adding SFM parameters to the BIM model, (3) retrieving data from the SFM database, and (4) transferring SFM data to the BIM model. Any BIM model creator should consider data compatibility with relevant SFM databases before creating new BIM models.

Two data transfer methods were evaluated. One relied entirely on manual data entry to transfer data from BUILDER SMS components to associated Revit elements. The other used manual entry of only a common identifier and automatic transfer using Select Queries for the rest. For the initial data transfer, method 1 took $1.21 \mathrm{~min}$ per component/element while method 2 took $0.89 \mathrm{~min}$. Subsequent data transfers could be completed in $4 \mathrm{~s}$ per component/element with method 2. Furthermore, method 2 does not require users to be familiar with the building in question after the initial transfer. Method 2 is best for frequent updates.

A focus group saw the SFM-enhanced BIM model as an aid to operation and maintenance of NJDMAVA facilities and suggested it should have a more significant role in facility management. The focus group was most interested in the visual capabilities of the SFM-enhanced BIM model, particularly the use of visual filters based on BUILDER SMS parameters and the possibility of viewing the BIM model and associated SFM information on a tablet/mobile device during site visits. 
Additional research in this area needs to be completed to further improve data transfer and better understand potential applications. Further testing of two-way transfer could be explored, as this study focused on transfer only from BUILDER SMS to Revit. This case study used a building that already had a completed basic Revit model and BUILDER SMS database. The proposed integrated workflow should be evaluated from start-to-finish, creating the BIM model from scratch with a BUILDER SMS compatible data structure. Additional data transfer methods should be evaluated, e.g., using an SQL database. Finally, the focus group mentioned the possibility of integrating the NJDMAVA work order system with BIM to improve the handling of maintenance requests. This could be accomplished following procedures similar to the integration workflow proposed here.

Supplementary Materials: The following are available online at https:/ / www.mdpi.com/article/10 $.3390 /$ su13137014/s1.

Author Contributions: Conceptualization, R.L., J.W.E., W.T.R., and D.B.C.; methodology, R.L., J.W.E., W.T.R., and D.B.C.; software, R.L.; validation, R.L. and J.W.E.; formal analysis, R.L.; investigation, R.L.; resources, J.W.E.; data curation, R.L.; writing—original draft preparation, R.L.; writing—review and editing, J.W.E., W.T.R., and D.B.C.; visualization, R.L.; supervision, J.W.E. and W.T.R.; project administration, J.W.E.; funding acquisition, J.W.E. and W.T.R. All authors have read and agreed to the published version of the manuscript.

Funding: This research was funded by the New Jersey Department of Military and Veteran Affairs as part of a contract titled Energy/Building Information Model (BIM)/Builder Internship Program.

Institutional Review Board Statement: Ethical review and approval were waived for this study, because the data collected via the focus group and survey were about a product and not about individuals, as per Rowan University IRB guidance 1.9H [48].

Informed Consent Statement: Not applicable.

Data Availability Statement: Data cannot be provided, in accordance with NJDMAVA policy [42].

Conflicts of Interest: The authors declare no conflict of interest.

\section{References}

1. Alexander, K. Facilities Management: Theory and Practice; Routledge: London, UK, 2013.

2. Nicał, A.; Wodyński, W. Enhancing Facility Management through BIM 6D. Procedia Eng. 2016, 164, 299-306. [CrossRef]

3. Pärn, E.; Edwards, D.; Sing, M. The building information modelling trajectory in facilities management: A review. Autom. Constr. 2017, 75, 45-55. [CrossRef]

4. Liu, R.; Issa, R.R.A. Automatically Updating Maintenance Information from a BIM Database. In Proceedings of the 2012 ASCE International Conference on Computing in Civil Engineering, Clearwater Beach, FL, USA, 17-20 June 2012; pp. 373-380.

5. Shalabi, S.F.; Turkan, A.Y. IFC BIM-Based Facility Management Approach to Optimize Data Collection for Corrective Maintenance. J. Perform. Constr. Facil. 2017, 31, 04016081. [CrossRef]

6. Pishdad-Bozorgi, P.; Gao, X.; Eastman, C.; Self, A.P. Planning and developing facility management-enabled building information model (FM-enabled BIM). Autom. Constr. 2018, 87, 22-38. [CrossRef]

7. Fennimore, J. Sustainable Facility Management: Operational Strategies for Today; Pearson: Boston, MA, USA, 2014.

8. BUILDER ${ }^{\text {TM }}$ Sustainment Management System. 2012. Available online: https://www.erdc.usace.army.mil/Media/Fact-Sheets/ Fact-Sheet-Article-View / Article/476728/builder-sustainment-management-system/ (accessed on 4 May 2020).

9. Ghaffarianhoseini, A.; Tookey, J.; Ghaffarianhoseini, A.; Naismith, N.; Azhar, S.; Efimova, O.; Raahemifar, K. Building Information Modelling (BIM) uptake: Clear benefits, understanding its implementation, risks and challenges. Renew. Sustain. Energy Rev. 2017, 75, 1046-1053. [CrossRef]

10. Eastman, C.M.; Teicholz, P.M.; Sacks, R.; Ghang, L. BIM Handbook a Guide to Building Information Modeling for Owners, Designers, Engineers, Contractors and Facility Managers; Wiley: Hoboken, NJ, USA, 2018.

11. NIBS. United States National Building Information Modeling Standard; National Institute of Building Sciences: Washington, DC, USA, 2007.

12. Bonanomi, M. Building Information Modeling (BIM) and Facility Management (FM). In Knowledge Management and Information Tools for Building Maintenance and Facility Management; Springer International Publishing: Cham, Switzerland, 2016; pp. 149-177.

13. Eadie, R.; Browne, M.; Odeyinka, H.; McKeown, C.; McNiff, S. BIM implementation throughout the UK construction project lifecycle: An analysis. Autom. Constr. 2013, 36, 145-151. [CrossRef]

14. Lu, Y.; Wu, Z.; Chang, R.; Li, Y. Building Information Modeling (BIM) for green buildings: A critical review and future directions. Autom. Constr. 2017, 83, 134-148. [CrossRef] 
15. Succar, B. Building information modelling framework: A research and delivery foundation for industry stakeholders. Autom. Constr. 2009, 18, 357-375. [CrossRef]

16. Yang, X.; Ergan, S. Leveraging BIM to Provide Automated Support for Efficient Troubleshooting of HVAC-Related Problems. J. Comput. Civ. Eng. 2016, 30, 04015023. [CrossRef]

17. Revit. Autodesk, Inc. Available online: https://www.autodesk.com/products/revit/overview (accessed on 18 June 2021).

18. Yin, X.; Liu, H.; Chen, Y.; Wang, Y.; Al-Hussein, M. A BIM-based framework for operation and maintenance of utility tunnels. Tunn. Undergr. Space Technol. 2020, 97, 103252. [CrossRef]

19. Ede, A.N.; Olofinnade, O.M.; Sodipo, J.O. Use of building information modelling tools for structural health monitoring. In Proceedings of the 2017 International Conference on Computing Networking and Informatics (ICCNI), Lagos, Nigeria, 29-31 October 2017; pp. 1-4.

20. Orr, K.; Shen, Z.; Juneja, P.K.; Snodgrass, N.; Kim, H. Intelligent Facilities: Applicability and Flexibility of Open BIM Standards for Operations and Maintenance. In Proceedings of the Construction Research Congress 2014: Construction in a Global Network-Proceedings of the 2014, Atlanta, GA, USA, 19-21 May 2014; Construction Research Congress: Atlanta, GA, USA, 2014; pp. 1951-1960. [CrossRef]

21. Lin, Y.-C.; Su, Y.-C. Developing Mobile- and BIM-Based Integrated Visual Facility Maintenance Management System. Sci. World J. 2013, 2013, 1-10. [CrossRef] [PubMed]

22. Wang, C.; Cho, Y.K.; Kim, C. Automatic BIM component extraction from point clouds of existing buildings for sustainability applications. Autom. Constr. 2015, 56,1-13. [CrossRef]

23. Lu, Q.; Chen, L.; Lee, S.; Zhao, X. Activity theory-based analysis of BIM implementation in building O\&M and first response. Autom. Constr. 2018, 85, 317-332. [CrossRef]

24. Mayo, G.; Issa, R.R.A. Nongeometric Building Information Needs Assessment for Facilities Management. J. Manag. Eng. 2016, 32, 04015054. [CrossRef]

25. Becerik-Gerber, B.; Jazizadeh, F.; Li, N.; Calis, G. Application Areas and Data Requirements for BIM-Enabled Facilities Management. J. Constr. Eng. Manag. 2012, 138, 431-442. [CrossRef]

26. Chong, H.-Y.; Lee, C.Y.; Wang, X. A mixed review of the adoption of Building Information Modelling (BIM) for sustainability. J. Clean. Prod. 2017, 142, 4114-4126. [CrossRef]

27. Wong, J.K.W.; Zhou, J. Enhancing environmental sustainability over building life cycles through green BIM: A review. Autom. Constr. 2015, 57, 156-165. [CrossRef]

28. Chong, H.-Y.; Wang, J.; Shou, W.; Wang, X.; Guo, J. Improving Quality and Performance of Facility Management Using Building Information Modelling; Springer Science and Business Media LLC: Berlin/Heidelberg, Germany, 2014; pp. 44-50.

29. Carbonari, G.; Stravoravdis, S.; Gausden, C. Improving FM task efficiency through BIM: A proposal for BIM implementation. J. Corp. Real Estate 2018, 20, 4-15. [CrossRef]

30. Gao, X.; Pishdad-Bozorgi, P. BIM-enabled facilities operation and maintenance: A review. Adv. Eng. Inform. 2019, 39, 227-247. [CrossRef]

31. Ilter, D.; Ergen, E. BIM for building refurbishment and maintenance: Current status and research directions. Struct. Surv. 2015, 33, 228-256. [CrossRef]

32. Kang, T.-W.; Choi, H.-S. BIM perspective definition metadata for interworking facility management data. Adv. Eng. Inform. 2015, 29, 958-970. [CrossRef]

33. McArthur, J. A Building Information Management (BIM) Framework and Supporting Case Study for Existing Building Operations, Maintenance and Sustainability. Procedia Eng. 2015, 118, 1104-1111. [CrossRef]

34. Antwi-Afari, M.; Li, H.; Parn, E.; Edwards, D. Critical success factors for implementing building information modelling (BIM): A longitudinal review. Autom. Constr. 2018, 91, 100-110. [CrossRef]

35. Volk, R.; Stengel, J.; Schultmann, F. Building Information Modeling (BIM) for existing buildings-Literature review and future needs. Autom. Constr. 2014, 38, 109-127. [CrossRef]

36. Chen, W.; Chen, K.; Cheng, J.C.; Wang, Q.; Gan, J. (Vincent) BIM-based framework for automatic scheduling of facility maintenance work orders. Autom. Constr. 2018, 91, 15-30. [CrossRef]

37. Zadeh, P.A.; Wang, G.; Cavka, H.B.; Staub-French, S.; Pottinger, R. Information Quality Assessment for Facility Management. Adv. Eng. Inform. 2017, 33, 181-205. [CrossRef]

38. Hu, Z.-Z.; Tian, P.-L.; Li, S.-W.; Zhang, J.-P. BIM-based integrated delivery technologies for intelligent MEP management in the operation and maintenance phase. Adv. Eng. Softw. 2018, 115, 1-16. [CrossRef]

39. Jupp, J.; Awad, R. BIM-FM and Information Requirements Management: Missing Links in the AEC and FM Interface. Lect. Notes Control Inf. Sci. 2017, 517, 311-323. [CrossRef]

40. ReCap. Autodesk, Inc. Available online: www.autodesk.com/products/recap/overview (accessed on 18 June 2021).

41. Army BUILDERTM SMS Inventory and Assessment Guide; Engineer Research \& Development Center: Vicksburg, MS, USA. Available online: https:/ / buildersummit.com/wp-content/uploads/2018/11/Army-BUILDER-SMS-Inventory-and-Assessment-Guide_ 20170629.pdf (accessed on 18 June 2021).

42. NJDMAVA Information Security Program. New Jersey Department of Military and Veterans Affairs. Departmental Directive 25.2.3; 2006. Available online: https:/ / www.nj.gov/military/publications/dd/DD25.2.3.pdf (accessed on 18 June 2021).

43. Microsoft Access. Available online: https:/ /www.microsoft.com/en-us/microsoft-365/access (accessed on 18 June 2021). 
44. Microsoft Excel. Available online: https://www.microsoft.com/en-us/microsoft-365/excel (accessed on 18 June 2021).

45. Autodesk Viewer. Available online: https://viewer.autodesk.com/ (accessed on 4 May 2020).

46. Giel, B.; Issa, R.R.A. Framework for Evaluating the BIM Competencies of Facility Owners. J. Manag. Eng. 2016, $32,04015024$. [CrossRef]

47. Charette, R.P.; Marshall, H.E. UNIFORMAT II Elemental Classification for Building Specifications, Cost Estimating, and Cost Analysis; NIST Interagency/Internal Report (NISTIR); National Institute of Standards and Technology: Gaithersburg, MD, USA, 1999.

48. Rowan University Guidebook Effective. 3 September 2020. Available online: https://research.rowan.edu/officeofresearch/ compliance/irb/policiesguidance/index.html (accessed on 21 June 2021). 